\title{
Grammatical Theory and Language Acquisition
}




\section{Publications in Language Sciences}

Publications in Language Sciences is a series of monographs in theoretical linguistics and its more formal satellite fields of scientific inquiry. It is intended to provide an opportunity for scholars working within these areas to report rapidly on research either terminated or in some definite stage of progress. Ideally, in these publications interest, inspiration and openmindness go hand in hand.

Ger J. de Haan

Wim Zonneveld

editors 


\section{LydiaWhite \\ Grammatical Theory \\ and Language \\ Acquisition}

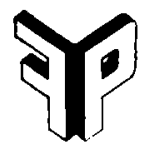

1982

FORIS PUBLICATIONS

Dordrecht - Holland/Cinnaminson - U.S.A. 
Published by:

Foris Publications Holland

P.O. Box 509

3300 AM Dordrecht, The Netherlands

Sole distributor for the U.S.A. and Canada:

Foris Publications U.S.A.

P.O. Box C-50

Cinnaminson N.J. 08077

U.S.A.

ISBN 9070176432 (Bound)

ISBN 9070176440 (Paper)

(9) 1982 Foris Publications - Dordrecht.

No part of this book may be translated or reproduced in any form, by print, photoprint, or any other means, without written permission from the publisher.

Printed in the Netherlands by Intercontinental Graphics, H.I. Ambacht. 